\title{
Editorial
}

\section{Algunas consideraciones sobre la investigación científica en Colombia}

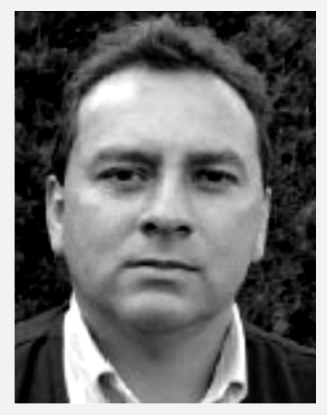

La revolución científica y tecnológica que vive el mundo nos obliga a reflexionar sobre el papel que cumple la educación, especialmente la superior, en el desarrollo de políticas que conlleven a una formación de calidad humanista, científica y técnica. Colombia no ha sido ajena a la valoración de los sistemas de ciencia y tecnología que se han establecido en el mundo, entre otras cosas, obedeciendo al reconocimiento económico que se le ha conferido al conocimiento, por cuanto se considera que el desarrollo científico, tecnológico y el uso de los medios informáticos son esenciales para obtener mayor ventaja en la competencia internacional.

Es importante reconocer los esfuerzos estatales que se registran en las dos últimas décadas en el país para impulsar el desarrollo tecnológico y la investigación. A través de Colciencias se han formalizado políticas encaminadas a consolidar la formación científica y tecnológica, con la financiación de proyectos, creación de grupos de investigación, becas y otorgamiento de préstamos para adelantar estudios de maestrías y doctorados en el exterior y formas de cooperación y convenios interinstitucionales con otros países.

Entre los criterios que hay para medir y evaluar las actividades de generación, aplicación e impacto del conocimiento que se produce en un país están: el número de patentes registradas y las publicaciones en revistas reconocidas por la comunidad científica. En ese sentido, en Latinoamérica, el país se ubica en el sexto lugar después Brasil, México, Argentina, Chile y Venezuela. En Colombia el mayor número de publicaciones corresponde a las ciencias exactas, las ciencias agrarias y las ciencias sociales. Igualmente se publica, aunque en menor proporción, en áreas como la lingüística, las letras y las artes.

En nuestro país la investigación se lleva a cabo principalmente en los centros universitarios estatales, siendo la Nacional, la del Valle y la de Antioquia las instituciones que desarrollan el mayor número de proyectos investigativos; de las privadas se destacan la Universidad de los Andes y la Pontificia Universidad Javeriana. Esta realidad muestra dos polaridades: las llamadas instituciones de elite investigativa, algunas de las cuales se han ganado un prestigio social importante y las universidades que poco o nada aportan en este campo.

1 Juan Francisco Miranda y Mónica Salazar Acosta. La construcción de una institucionalidad y una política en ciencia y tecnología. En Ciencia y tecnología Vol 24, 2006, Pg 6. 
Por otra parte, el año anterior, en uno de los diarios locales más importantes, un artículo mostraba cómo sólo una universidad latinoamericana, la Autónoma de México (UNAM) figuraba entre las mejores del mundo. La no presencia de universidades colombianas en esa lista, se asocia, entre otros factores, al bajo número de profesionales con estudios de maestría y doctorado con que cuenta el país. Según datos de la UNESCO por cada 1000 habitantes debe haber un profesional con doctorado y en Colombia bien contados, no llegan a 5000. Este número sigue siendo muy inferior al que se considera deseable para la población y para el número de programas académicos existentes. Además de incrementar y fortalecer los programas de maestrías y doctorados, para la formación de científicos, es necesario repensar y revaluar varios aspectos:

1. Desde lo estatal, la inversión destinada a la investigación debe ser mayor, ya que estamos por debajo de países como Brasil, México y Argentina. La meta en la inversión nacional en ciencia, tecnología e innovación (CTI) es llegar al 1\% del PIB en el año $2010^{1}$. Además, se necesitan mayores incentivos económicos y sociales para quienes se dedican exclusivamente a la investigación, para que no tengan que buscar nuevos horizontes en otros países. Lo anterior se hace extensivo a todo el personal docente, quienes necesitan unas condiciones salariales y prestacionales favorables, para un desempeño eficiente de su labor formativa e investigativa.

2. Desde las universidades, uno de los aspectos relevantes a considerar, es la necesidad de continuar reconociendo y consolidando los cuerpos académicos, ya que ellos son la fuerza motriz del desarrollo institucional y sobre ellos recae la responsabilidad de contribuir a la construcción de ambientes adecuados que garanticen el cumplimiento de los objetivos institucionales. Si bien es imperante una formación académica y un aumento en el número de docentes que atienda la demanda estudiantil universitaria, estos aspectos no son suficientes para mejorar la calidad de la educación superior; se requiere un gran esfuerzo de cualificación que abarca otras dimensiones:

a. El trabajo en equipo, considerado un factor que permite mejores formas de producción en el campo científico y humanístico, implica contar con capacidades de comunicación y sensibilidad social, hacer frente a las incertidumbres, tener un espíritu de empresa, estar dispuestos a asumir y compartir responsabilidades con actitud crítica y desarrollar aptitudes para resolver problemas de manera conjunta. La conformación de equipos de trabajo interdisciplinarios intra e interinstitucionales, combate, de cierta manera, el trabajo aislado que todavía prevalece en muchas universidades. 
b. Las redes académicas universitarias y la movilidad que se genera tanto en el personal docente como en el estudiantil a nivel nacional e internacional, puede ayudar a consolidar las líneas de investigación, que desde el pregrado se deben establecer, con el fin de apuntalar la realización de proyectos de investigación conjuntos, donde se aproveche las fortalezas de cada una de las instituciones. De esta manera sería posible consolidar verdaderos grupos investigativos que generen líneas de trabajo atendiendo a las necesidades reales y sentidas del país. Lo anterior permitiría que las actividades de las universidades estuvieran encaminadas a la generación y aplicación del conocimiento y no se centrara en la transmisión del mismo. Esto repercutiría de manera directa en un cambio de concepción de ciencia e investigación y ayudaría a que los resultados de las tesis de grado, además de publicarse en revistas indexadas, tuvieran una aplicación y un impacto importante y no se perdieran en los anaqueles.

c. La relación entre universidad y empresa, es decir, entre el mundo laboral y la educación superior, con el fin de hallar un equilibrio entre la labor que conlleve la búsqueda del conocimiento y la atención a necesidades sociales que respondan a expectativas y problemáticas reales y sentidas. Al respecto las pasantías son un buen camino, pero aún falta un mayor compromiso, especialmente de la empresa privada, que permita gestionar, desarrollar y apoyar económicamente proyectos investigativos.

d. La educación, como actividad humana intencional, incluye, como una de sus partes esenciales, procesos evaluativos continuos. Estos deben cobijar a los programas, proyectos y acciones que se emprenden, y que en el caso de las universidades se pueden sintetizar en tres aspectos: el primero, la pertinencia, es decir la coherencia del proyecto educativo institucional y de sus planes de estudio con las necesidades y las características del área de influencia de la institución. El segundo, la eficacia, entendida como la coherencia entre las actividades desarrolladas por la institución para cumplir sus metas y los objetivos de cada uno de los programas. El tercero, la efectividad, vista como una relación entre los recursos invertidos, el esfuerzo desplegado y el tiempo empleado para el logro de los objetivos de los programas, que deben estar en correspondencia con los fines de la institución.

e. Se espera una innovación continua tanto en el ámbito educativo como en los procesos de gestión. Se requiere que las instituciones se constituyan como organizaciones de aprendizaje permanente, que innoven sus procesos y estructuras acordes con las condiciones cambiantes del entorno social y con el reto que impone las nuevas exigencias en los sistemas educativos, entre ellos, asumir que la educación superior amplía su misión a la formación de profesionales con capacidad de liderazgo, espíritu investigativo y prospectiva empresarial. 
f. El uso de las nuevas tecnologías, sistemas de información y comunicación posibilitan oportunidades para acceder y mejorar las formas de producción, organización, difusión y control del conocimiento. En este sentido, surge la necesidad de garantizar un acceso equitativo a estas tecnologías en todas las instituciones universitarias del país. Esto permitirá, entre otras cosas, constituir redes y bancos de información, diseño de material didáctico, transferencias tecnológicas y fortalecimiento de las funciones de servicio a la comunidad que tienen las universidades, a través de medios de información que garanticen la difusión y apropiación social del conocimiento.

Para terminar, en un país donde la investigación y producción de conocimiento se genera, especialmente, en las instituciones de educación superior, son las universidades las llamadas a formar técnicos, profesionales y científicos altamente calificados que den respuesta a los desafíos, que en distintos campos esta sociedad plantea. De manera concomitante con una sólida formación académica, es fundamental la formación de ciudadanos críticos y comprometidos con sus comunidades y conscientes de las oportunidades que se presentan para construir un país que brinde mejores oportunidades de bienestar a toda la población. Valdría la pena realizar estudios que conlleven a analizar el impacto de los programas de formación en este nivel en las instituciones de educación superior en nuestro país.

Rubinstein Hernández Barbosa Asistente Editorial, NOVA Publicación Científica en Ciencias Biomédicas Coordinador del Área de Ciencias y Educación Ambiental del Gimnasio Moderno, Bogotá, Colombia MSc. en Biología, PUJ. 